\title{
Dental implants characteristics, stability and designs
}

\author{
Alaa Almalki ${ }^{1 *}$, Mohammed Albati², Mohammed Alhijaili ${ }^{2}$, Ahmad Hariri ${ }^{2}$, \\ Hydar Alnowaisser ${ }^{3}$, Ali Salem ${ }^{4}$, Ibrahim Alibrahim ${ }^{4}$, Redwan Alfattany ${ }^{5}$, \\ Mujtaba Alnowaisser ${ }^{6}$, Ebtihal Alshahrani ${ }^{7}$
}

\author{
${ }^{1}$ College of Dentistry, Jordan University of Science and Technology, Irbid, Jordan \\ College of Dentistry, ${ }^{2}$ AlFarabi Colleges, Jeddah; ${ }^{5}$ Jazan University, Jazan; ${ }^{7}$ King Khalid University, Abha, Saudi \\ Arabia \\ ${ }^{3}$ Al Moalmein Primary Health Care, Ministry of Health, Al-Ahsa, Saudi Arabia \\ ${ }^{4}$ Faculty of Dentistry, Umm Al-Qura University, Mecca, Saudi Arabia \\ ${ }^{6}$ Primary Health Care, Ministry of Health, Tabuk, Saudi Arabia
}

Received: 19 August 2018

Accepted: 06 September 2018

\section{*Correspondence:}

Dr. Alaa Almalki,

E-mail: dr.alaa-almalki@hotmail.com

Copyright: () the author(s), publisher and licensee Medip Academy. This is an open-access article distributed under the terms of the Creative Commons Attribution Non-Commercial License, which permits unrestricted non-commercial use, distribution, and reproduction in any medium, provided the original work is properly cited.

\begin{abstract}
One of the recent advances in the field of dentistry is to provide prothesis that can replace lost natural teeth. Over several decades, researches were endeavouring to create dental implants with optimized criteria that allow long-term function and stability. After notable success, the use of dental implant has become an almost daily routine in dental practice. However, many factors can influence the success of dental implantation procedures. Primary implant stability remains the most reliable predictor of dental implants success, and many factors are known to have a considerable impact on the implant stability such as the thread morphology, the implant size and length, the implant body shape, the surgical technique use, and the underlying bone heath. Knowledge of these factors is essential for optimizing the outcome of dental implantation procedures even in unfavourable conditions. Therefore, this article aims at reviewing and discussing the various dental implants designs, characteristics, and stability.
\end{abstract}

Keywords: Characteristics, Dental implants, Designs, Morphology, Stability

\section{INTRODUCTION}

One of the recent advances in the field of dentistry is to provide prothesis that can replace lost natural teeth. Over several decades, researches were endeavouring to create dental implants with optimized criteria that allow longterm function and stability. ${ }^{1}$ Years of experience had resulted in production of various successful types of removable and fixed dental protheses for partially or fully edentulous patients. ${ }^{2}$ Currently, the use of dental implant has become an almost daily routine in dental practice. Though the success rate of the vast majority of dental implants is generally high (around 90\%), it varies according to many factors. ${ }^{3-5}$ These factors are either biological factors or biomechanical factors. Biological factors responsible for dental prothesis are responsible for higher complications rate than biomechanical factors, but both should be considered during the evaluation process. ${ }^{6}$ The main biomechanical factors include the dental implant design, characteristics, biomechanics, the material of the implant, the host bed, the bone feature at the site of implant insertion, and the surgical technique. ${ }^{1,3,7}$

This article aims at reviewing and discussing the various dental implants designs, characteristics, and stability. 


\section{DENTAL IMPLANTS CHARACTERISTICS AND DESIGNS}

Dental implants have witnessed a notable advance in their design. In the past, primitive dental implants were blade, staple, periosteal types of dental protheses that were associated with high failure rates due to their poor biomechanics. ${ }^{8}$ Recently, major developments were made in the morphology, structure, and design of dental implants to improve their biomechanical properties, stability, and long-term success. The current structure of any dental implant is composed of four elements: the implant body, the screw, the healing abutment, and the transmucosal abutment. ${ }^{9}$ The body is the main component of any dental implant and it is manufactured in various shapes. Some bodies are screw-shaped (cylindrical or straight), others have a tapered shape (conical), and the rest have a hexagonal shape. The body is the part of the implant that is inserted inside the bone. ${ }^{10}$ The hexagonal implants are resistant to rotation, whereas the tapered ones are well-sealed. The implant body contains a neck (with or without micro threads), and it is available in variable sizes $(3.75$ to $5.0 \mathrm{~mm}$ ) and lengths $(10-15 \mathrm{~mm})$. After the body is implanted inside the bone, a screw is used for fixation. Once osseointegration occurs, the screw is removed, and a healing abutment is screwed instead. This is performed to maintain viability and health of the mucosa. ${ }^{9}$ A transmucosal abutment kinks the body with a dental prothesis always made of titanium. Titanium is a strong compound with physical, chemical, and mechanical properties appropriate for resisting corrosion, repetitive mechanical shearing, and chemical resistance. The surface of the implant may be acid-etched, machined, or anodized, and the substrate may be polyurethane or polytetrafluoroethylene. ${ }^{11,12}$

Dental implant design is one of the mainstay factors responsible for the primary stability of the dental prosthesis. ${ }^{12}$ It is also fundamental for the dental implant to sustain loading during the process of osseointegration. ${ }^{11}$ Basically, there are two designs of dental implants: the micro-design and the macro-design. The micro-design is specifically concerned with the morphology of the dental implant surface, whilst the macro-design focuses on the implant body shape, the thread pitch, and the thread morphology. ${ }^{13}$ As regards the macro-design, the shape of the dental implant mainly affects the loading on the bone site and the bone response to the implant. It also determines the implant surface area in contact with the bone and the amount of stress transferred to the bone. ${ }^{14}$ For instance, the implant length is a determinant of primary stability. The larger the length, the better the stability. However, increased length may interfere with the process of healing abutment application. ${ }^{14}$ The implant size is more important than its length and is considered a direct predictor of implant strength. The shape of the implant is also important as will be mentioned in the next section e.g. tapered screws are associated with better primary stability than screwed implants. ${ }^{15}$ Regarding the micro-design, thread pitch, depth, and diameter are the most important factors affecting the dental implant function. ${ }^{16}$ Threat pitch is a determinant of the implant surface area in contact with the bone, the threat shape determines the direction and load from the prothesis to the underlying bone, and the threat pitch determines both the stress applied by the implant and surface area in contact with the bone. ${ }^{17}$

\section{DENTAL IMPLANTS STABILITY}

Primary stability of dental implant has long been established to be the most reliable predictor for successful dental prothesis implantation. ${ }^{18}$ Patients with inadequate primary stability of dental implants were reported to have high implant failure rates occurring in up to one third of the cases. ${ }^{19}$ Dental implant stability is essential to minimize the inflammatory tissue response to implant motion and the subsequent fibrous tissue formation that interfere with the healing process. ${ }^{18}$ Previous researches emphasized the importance of adequate primary instability for immediate and early loading. However, a range of minimal motion is allowed for proper stability of an implant. Literature studies reported that an accepted amplitude of motion ranges from 50 to $15000 \mu \mathrm{m} .^{20}$ However, a measure between 60-65 carries a good predictive value for early implant loading and procedural success. ${ }^{19}$ This range is determined by the implant morphology, surface features, and design. The dental implant motion is generally measured clinically via percussion, mobility tests, or dental radiographs. Reliable quantitative measurement of dental implant micromotion can be carried out by a small transducer fastened the dental implant inserted via a technique called resonance frequency analysis. ${ }^{21}$

Experimental research has found that the main factors responsible for primary implant stability are the implant design, the implant characteristics, the bone feature at the site of implantation of the dental prothesis, and the surgical technique adopted during the implantation procedure. ${ }^{13}$ Knowledge of such factors had resulted in notable advances in the dental implantation procedures. Dentists became able to choose the proper surgical technique, the suitable dental implant design, and appropriate implant morphology to optimize the results of their implantation procedures even if the medical condition, the bone site of implantation, or the general bone health were of unfavourable prognosis.

Dental implant design is the most commonly reported to affect primary dental stability and the outcome of osseointegration process. Sergio et al, in their study comparing the impact of two different implantation techniques on the primary implant stability, reported that conical implants had higher stabilization rates than semiconical implants. ${ }^{13}$ This was thought to be attributed to their higher surface area in contact with the mandibular bone and their more prominent thread at their apical part. The thread width, thickness, and pitch were reported to be other important independent factors in determining the 
dental implant primary stability. Implants with wider and thicker threads with a decreased screw pitch were associated with higher stability rates. ${ }^{22-24}$

Along with the implant design, the surgical technique used for implantation is fundamental. Torque insertion and removal method was reported to significantly affect the primary stability. ${ }^{25}$ Various studies compared the impact of using a press-fit versus undersized torque insertion techniques on primary implant stability. ${ }^{25}$ Torque insertion can change the last drilling size and, therefore, provide an alternative protocol of dental implantation in cases with poor bone condition. Torque insertion depends largely on the preparation method. Undersized techniques are associated with better primary stability in comparison to the standard techniques. ${ }^{26}$ Additionally, torque insertion of tapered dental implants was reported to be superior to straight implants insertion. ${ }^{19}$

Other factors that were reported to affect the primary stability of dental implants include the loading conditions, the host bed features, and the material biocompatibility. ${ }^{26}$ Bone quality is an important predictor of primary stability, and it was reported that the primary implant stability was directly correlated with the bone density and quality. ${ }^{27}$ Natural and stimulated bones were proposed to influence the stability of dental implants. However, to date, no adequate data are available to confirm or negate this theory. ${ }^{25}$

All the factors that affect the dental implant stability seem to interact with each other and influence each other. $^{25,28}$ Therefore, it is essential for dentists to understand these factors and to be well-educated and trained about how to apply them adequately during dental implantation procedures to achieve successful osseointegration and minimize implantation failure.

\section{CONCLUSION}

Dental implant designs and morphology have a considerable impact on the implant stability and implantation success. Many factors can influence the primary stability such as the thread morphology, the implant size and length, the implant body shape, the surgical technique use, and the underlying bone heath. Knowledge of these factors is essential for optimizing the outcome of dental implantation procedures even in unfavourable conditions.

Funding: No funding sources Conflict of interest: None declared Ethical approval: Not required

\section{REFERENCES}

1. Steigenga JT, Al-Shammari KF, Nociti FH, Misch CE, Wang HL. Dental implant design and its relationship to long-term implant success. Implant Dent. 2003;12(4):306-17.

2. Misch CE. Dental Implant Prosthetics. $2^{\text {nd }}$ Edition. Elsevier. 2014.

3. Simonis P, Dufour T, Tenenbaum H. Long-term implant survival and success: A 10-16-year followup of non-submerged dental implants. Clin Oral Implants Res. 2010;21(7):772-7.

4. Misch CE, Perel ML, Wang HL, Sammartino G, Galindo-Moreno P, Trisi P, et al. Implant success, survival, and failure: The International Congress of Oral Implantologists (ICOI) pisa consensus conference. Implant Dent. 2008;17(1):5-15.

5. Annibali S, Cristalli MP, Dell'Aquila D, Bignozzi I, La Monaca G, Pilloni A. Short dental implants: A systematic review. J Dent Res. 2012;91(1):25-32.

6. Misch CE. Stress Treatment Theorem for Implant Dentistry: The Key to Implant Treatment Plans. Biological versus Biomechanical. In: Dental Implant Prosthetics; 2013.

7. Sakka S, Baroudi K, Nassani MZ. Factors associated with early and late failure of dental implants. J Investig Clin Dent. 2012;3(4):258-61.

8. Misch CE, Strong JT, Bidez MW. Scientific Rationale for Dental Implant Design. In: Dental Implant Prosthetics; 2014.

9. Oshida Y, Tuna EB, Aktören O, Gençay K. Dental implant systems. Int J Mol Sci. 2010;11(4):1580678.

10. Yamanishi Y, Yamaguchi S, Imazato S, Nakano T, Yatani H. Influences of implant neck design and implant-abutment joint type on peri-implant bone stress and abutment micromovement: Threedimensional finite element analysis. Dent Mater. 2012;28(11):1126-33.

11. Jokstad A, Braegger U, Brunski JB, Carr AB, Naert I, Wennerberg A. Quality of dental implants. Int Dent J. 2003;53(6):409-43.

12. Gaviria L, Salcido JP, Guda T, Ong JL. Current trends in dental implants. J Korean Assoc Oral Maxillofac Surg. 2014;40(2):50-60.

13. Gehrke SA, da Silva UT, Del Fabbro M. Does Implant Design Affect Implant Primary Stability? A Resonance Frequency Analysis-Based Randomized Split-Mouth Clinical Trial. J Oral Implantol. 2015;41(6):281-6.

14. Baggi L, Cappelloni I, Di Girolamo M, Maceri F, Vairo G. The influence of implant diameter and length on stress distribution of osseointegrated implants related to crestal bone geometry: A threedimensional finite element analysis. J Prosthet Dent. 2008;100(6):422-31.

15. Jones AA, Cochran DL. Consequences of Implant Design. Dent Clin North Am. 2006;50(3):339-60.

16. Abuhussein H, Pagni G, Rebaudi A, Wang HL. The effect of thread pattern upon implant osseointegration: Review. Clin Oral Implants Res. 2010;21(2):129-36. 
17. Vidyasagar L, Apse P. Dental Implant Design and Biological Effects on Bone-Implant Interface. Stomatol Balt Dent Maxillofac J. 2004;6:51-4.

18. Javed F, Ahmed HB, Crespi R, Romanos GE. Role of primary stability for successful osseointegration of dental implants: Factors of influence and evaluation. Interv Med Appl Sci. 2013;5(4):162-7.

19. Javed F, Romanos GE. The role of primary stability for successful immediate loading of dental implants. A literature review. J Dent. 2010;38(8):612-20.

20. Gao SS, Zhang YR, Zhu ZL, Yu HY. Micromotions and combined damages at the dental implant/bone interface. Int J Oral Sci. 2012;4(4):182-8.

21. Ostman P-O, Hellman M, Wendelhag I, Sennerby L. Resonance frequency analysis measurements of implants at placement surgery. Int J Prosthodont. 2006;19(1):77-83.

22. Ryu H-S, Namgung C, Lee J-H, Lim Y-J. The influence of thread geometry on implant osseointegration under immediate loading: a literature review. J Adv Prosthodont. 2014;6(6):547-54.

23. Geurs NC, Jeffcoat RL, McGlumphy E, Reddy MS, Jeffcoat MK. Influence of implant geometry and surface characteristics on progressive osseointegration. Int $\mathbf{J}$ Oral Maxillofac Implants. 2002;17(6):811-5.

24. Orsini E, Giavaresi G, Trirè A, Ottani V, Salgarello S. Dental implant thread pitch and its influence on the osseointegration process: an in vivo comparison study. Int $\mathrm{J}$ Oral Maxillofac Implants. 2012;27(2):383-92.

25. Eliasa CN, Rocha FA, Nascimento AL, Coelho PG. Influence of implant shape, surface morphology, surgical technique and bone quality on the primary stability of dental implants. J Mech Behav Biomed Mater. 2012;16:169-80.

26. Ahn SJ, Leesungbok R, Lee SW, Heo YK, Kang KL. Differences in implant stability associated with various methods of preparation of the implant bed: An in vitro study. J Prosthet Dent. 2012;107(6):36672.

27. Farré-Pagès N, Augé-Castro ML, Alaejos-Algarra F, Mareque-Bueno J, Ferrés-Padró E, HernándezAlfaro F. Relation between bone density and primary implant stability. Med Oral Patol Oral Cir Bucal. 2011;16(1):62-7.

28. Lioubavina-Hack $\mathrm{N}$, Lang NP, Karring $\mathrm{T}$. Significance of primary stability for osseointegration of dental implants. Clin Oral Implants Res. 2006;17(3):244-50.

Cite this article as: Almalki A, Albati M, Alhijaili M, Hariri A, Alnowaisser H, Salem A, et al. Dental implants characteristics, stability and designs. Int $\mathbf{J}$ Community Med Public Health 2018;5:4625-8. 